\title{
Incidence of incidental carcinoma gall bladder in cases of routine cholecystectomy
}

\author{
Ghimire $\mathrm{P}^{1,2}$ Yogi $\mathrm{N}^{1}$ Shrestha $\mathrm{BB}^{1}$
}

${ }^{1}$ Department of Surgery, Manipal Teaching Hospital, Pokhara, Nepal.

${ }^{2}$ Department of Surgery, Fishtail Hospital and Research Center, Pokhara, Nepal

Corresponding Author

Dr. Pradeep Ghimire MS, FRCS ED

Fishtail Hospital and Research Center, and

Manipal Teaching Hospital

Pokhara, Nepal.

Email: pradeepg757@hotmail.com

Citation

Ghimire P, Yogi N, Shrestha BB. Incidence of incidental carcinoma gall bladder in cases of routine cholecystectomy. Kathmandu Univ Med J 2011;34(2)3-6.

\begin{abstract}
Background

Carcinoma of gall bladder is the most common malignancy of the billiary tract. Most of the cases are diagnosed as an incidental case among patients undergoing cholecystectomy.
\end{abstract}

\section{Objectives}

To establish the rate of incidental carcinoma of gall bladder in patients undergoing routine cholecystectomy to study the demographic profile and prognosis of these patients.

\section{Methods}

A retrospective study was carried out in Fishtail Hospital and Research Center, Pokhara during 1998-2009. The surgical notes, hospital records and histopathology reports of 783 patients undergoing routine cholecystectomy were studied.

\section{Results}

Out of 783 cases, gall bladder cancer was detected in 10(1.28\%) of cases and was more common in females (M:F ratio 1:2.3) and the mean age of occurrence was 63.8 years. Most of the cases diagnosed were at their early stages and none of them were in T3 and T4 stages. Six of these patients have survived till a mean follow up duration of 23.7 months.

\section{Conclusion \\ The rate of incidental carcinoma of gall bladder is $1.28 \%$.}

KEY WORDS

carcinoma gallbladder, cholecystectomy, incidental

\section{INTRODUCTION}

Cholecystectomy is the most common major abdominal procedure performed worldwide. In US, annual incidence of gall bladder disease is estimated around 1 million amongst which 500-600 thousand cases are operated annually.1 Carcinoma of gallbladder is the 5 th most common cancer of digestive tract and the most common malignancy of the biliary tract.2,3 The clinical manifestations of gall bladder carcinoma are generally indistinguishable from those associated with cholecystitis or cholelithiasis. Around 90\% of GB (Gall bladder) carcinoma have accompanying stone. 4 Stones and chronic inflammation are the risk factors for carcinoma of gallbladder. However, only $0.5-3 \%$ of patients with cholelithiasis will develop gallbladder cancer. 5
Most of the cases of GB carcinoma are diagnosed during or after surgery performed for stones or benign biliary diseases. 6 Despite advancements in various diagnostic procedures, preoperative diagnosis of GB carcinoma is an exception rather than the rule, occurring in fewer than $20.0 \%$ of patients.7 Advanced stage of the disease because of delayed diagnosis leads to its poor prognosis except when diagnosed at early stages incidentally during routine cholecystectomies. Thus some of the surgeons recommend surgery even for the patient with asymptomatic gall bladder stones because of its likelihood to harbour occult malignancy. 8 Role of histopathology of gall bladder specimen after routine cholecystectomy has 
also been challenged by various investigators stating that macroscopic features are always present in cases of GB carcinoma which can be used to selectively send specimens for histopathology.9,10,11

The aim is to study the frequency of incidental carcinoma of gall bladder in patients undergoing routine cholecystectomy and to study the demographic profile and prognosis of these patients.

\section{METHODS}

A retrospective study was done on all routine cholecystectomy cases ( $n=783$ ) performed from 1998-2009 in Fishtail Hospital and Research Center, Pokhara, Nepal. The surgical case notes including the preoperative entry, the operating notes and all clinical information and the histopathological reports of the patients and their follow up were evaluated. The incidence and clinicopathogical factors (presenting symptoms, demographics, histopathology, staging and follow up) of gallbladder carcinoma that were detected incidentally during routine cholecystectomy were reviewed and analysis was done using SPSS11.5 software. The results were tabulated and a through review of literature was done. All the cases in which cholecystectomy was done but had any suspicion of malignancy during preoperative evaluation was excluded from the study. The study was ethically approved by the ethical committee of our hospital.

\section{RESULTS}

A total of 783 cholecystectomies were performed during the study period. Most of the cases (99.23\%) were acute or chronic calculus cholecystitis. Six patients were operated for gall bladder polyp. Out of the 777 cases having cholecystitis; 33 patients also had associated choledocholithiasis, 2 patients had Mirrizi syndrome Type II and 5 patients had cholecystoduodenal fistula. Most common presentation were pain in epigastric region (70.11\%), dyspepsia (62.84\%), nausea or vomiting (56.96\%) and anorexia (44.57\%) (Table 1).

Table 1. Signs and symptoms of patient undergoing cholecystectomy.

\begin{tabular}{ll}
\hline Symptoms/Signs & Frequency \\
\hline Pain in epigastric region & $549(70.11 \%)$ \\
\hline Dyspepsia & $492(62.84 \%)$ \\
\hline Nausea/Vomiting & $446(56.96 \%)$ \\
\hline Anorexia & $349(44.57 \%)$ \\
\hline Rt upper quadrant pain & $219(27.97 \%)$ \\
\hline Fever & $132(16.86 \%)$ \\
\hline Murphy's sign positive & $53(6.77 \%)$ \\
\hline Jaundice & $35(4.47 \%)$
\end{tabular}

There were 147 males and 636 females with female: male ratio being 4.33:1. The age of the patients ranged from 8 years to 89 years old.

A total of 10 patients (1.28\%), 3 male and 7 female were diagnosed to have carcinoma GB on histopathological examination of the GB specimen. The female: male ratio was 2.33:1. The age ranged between 42 to 83 years with mean age being 63.8 years.

None of the cases were suspected pre or intra-operatively to have GB carcinoma despite of thorough investigation preoperatively including liver function tests, routine blood tests, USG of abdomen and pelvis in all cases and CT scan abdomen whenever required. Out of the 10 cases of GB carcinoma 8 were adenocarcinoma and 2 were adenosquamous carcinoma. Eight patients had associated stone whereas 2 cases had GB polyp but no stones. None of the cases had metastasis or involvement of the regional lymph nodes histologically. Eight cases were pathologically staged as T1 whereas two were staged as T2. Out of these two cases re-exploration with resection of segment $4 a$ and $5 \mathrm{~b}$ was done in one case with $\mathrm{T} 2$ disease whereas the other case denied further surgery in view of prognosis and the

Table 2. Clinical and histological findings of incidental carcinoma GB.

\begin{tabular}{|c|c|c|c|c|c|c|c|}
\hline Age & Sex & Intraoperative Finding & Stone & Type of tumour & Stage $(T)$ & Status & Duration(since diagnosis) \\
\hline 47 & $\mathrm{~F}$ & CCC, Mirizzi & yes & Adenocarcinoma & T1a & Alive, Well & 33 months \\
\hline 69 & $\mathrm{~F}$ & Thickened wall & yes & Adenocarcinoma & $\mathrm{T} 1 \mathrm{~b}$ & $\begin{array}{l}\text { Alive, Loss of weight and apetite, No } \\
\text { metastasis }\end{array}$ & 11 months \\
\hline 63 & $\mathrm{~F}$ & ACC & yes & $\begin{array}{l}\text { Adenosquamous } \\
\text { carcinoma }\end{array}$ & T1a & Alive, well & 24 months \\
\hline 57 & $\mathrm{~F}$ & Polyploid mass & No & Adenocarcinoma & $\mathrm{T} 1 \mathrm{~b}$ & Died & 17 months (Trauma) \\
\hline 82 & $\mathrm{~F}$ & $\mathrm{CCC}, \mathrm{CBD}$ stone & yes & $\begin{array}{l}\text { Adenosquamous } \\
\text { carcinoma }\end{array}$ & $\mathrm{T} 2$ & Died, denied further surgery or chemo & 8 months \\
\hline 73 & $\mathrm{M}$ & $\mathrm{CCC}$ & yes & Adenocarcinoma & $\mathrm{T} 1 \mathrm{~b}$ & Alive, well & 36 months \\
\hline 49 & $\mathrm{~F}$ & $\mathrm{CCC}$ & yes & Adenocarcinoma & T1b & Alive, well & 23 months \\
\hline 76 & $\mathrm{M}$ & Polyploid mass & No & Adenocarcinoma & $\mathrm{T} 2$ & Alive, well & 12 months \\
\hline 42 & $\mathrm{M}$ & CCC, CBD stone & yes & Adenocarcinoma & T1a & Died & 38 months \\
\hline 80 & $\mathrm{~F}$ & $\mathrm{CCC}$ & yes & Adenocarcinoma & $\mathrm{T} 1 \mathrm{~b}$ & Died & 13 months (MI) \\
\hline
\end{tabular}

$\mathrm{CCC}=$ Chronic Calculus Cholecystitis; $\mathrm{CBD}=$ Common Bile Duct; $\mathrm{Ml}=$ Myocardial Infarction 
Table 3. List of various studies showing incidence of incidental carcinoma GB.

\begin{tabular}{|c|c|c|c|c|c|c|}
\hline Studies & Year & Place & Sample size & M:F & Mean age (yrs) & Incidence (GB ca) \\
\hline Daphna et al ${ }^{21}$ & - & Israel & 1697 & $1: 5$ & 70 & $0.3 \%$ \\
\hline Khoo JJ \& Nurul AM 22 & $2000-2005$ & Malaysia & 1122 & $1: 2$ & 56.7 & $0.62 \%$ \\
\hline Mittal R et al ${ }^{9}$ & $1998-2007$ & India & 1305 & $1: 5.5$ & 56.2 & $0.99 \%$ \\
\hline Zhang WJ et al ${ }^{19}$ & 1999-2007 & China & 10,466 & $1: 4$ & 65.7 & $0.19 \%$ \\
\hline Amanullah et al $^{17}$ & $2000-2002$ & India & 428 & $1: 7$ & 47 & $1.87 \%$ \\
\hline Shrestha $\mathrm{R}$ et al ${ }^{18}$ & 2003-2007 & Nepal & 570 & $1: 3.5$ & 53.56 & $1.4 \%$ \\
\hline Naqvi et al ${ }^{20}$ & $1985-2004$ & Pakistan & 1109 & $1: 4.4$ & - & $5.9 \%$ \\
\hline Present Study & 1998-2009 & Nepal & 783 & $1: 2.3$ & 63.8 & $1.28 \%$ \\
\hline
\end{tabular}

age of the patient. All the cases were further consulted with oncologist for further adjunctive therapy.

Out of the 10 cases of incidental carcinoma GB, two patients died at 13 and 17 months of diagnosis due to causes unrelated to GB carcinoma; two patients died due to metastatic disease. $6(60 \%)$ of the patient have still survived at a mean follow up duration of 23.17 months. The details of the 10 cases of incidental carcinoma GB has been described in Table 2.

\section{DISCUSSION}

Though Gallstones are very often implicated with gall bladder carcinoma; other factors implicated to increase the risk include porcelain gallbladder, adenomatous polyps of the gallbladder, chronic infection with Salmonella typhi, carcinogen exposure (e.g., miners exposed to radon), and abnormal pancreaticobiliary duct junction (APBDJ). 5 Most of the cases of carcinomna GB are diagnosed at advanced stage and have a poor prognosis having 5 year survival rate of $<5 \%$. When detected at early stages prognosis may improve significantly up to $90-100 \%$ five years survival rate.12,13 However these carcinomas are known to have delayed onset of symptoms. They are also usually diagnosed as incidental finding post cholecystectomy and theoretically this group carries the best prognosis.14 In our series, $60 \%$ of our patients with incidental carcinoma had survived till a mean follow up duration of 23.17 months.

In our series the incidence rate of incidental GB carcinoma in routine post-cholecystectomy cases was $1.28 \%$. Amanullah et al (1.8\%) and Shrestha $\mathrm{R}$ et al (1.4\%) have found the incidence similar to ours whereas Zhang WJ et al has shown its occurrence as low as $0.19 \%$ and Navqi et al has found its occurrence as high as 5.9\%.15-18 The list of various authors with the variety in their observation of occult carcinoma of GB is listed in Table 3.9,15-20 The variety in the incidence may be due to inadequate preoperative evaluation or less number of cholecystectomy used for the study purpose. This is because the incidence of primary carcinoma of the gall bladder is itself low. Most of the patient with incidental carcinoma GB were female (M:F ratio 1:2.33) and the mean age was 63.8 years. Most of the studies listed in table 3 show similar pattern of findings.

It is a standard practice to perform routine histopathological examinations for all cholecystectomy specimens. Various studies including the working report of Royal College of Pathologists have recommended for this routine standard practice.15,21 Recently few other investigators have challenged this practice. They have suggested that all cases of GB carcinoma have some macroscopic features like thickened fibrotic wall, mucosal ulceration, nodular mucosa or polyploidy projections which can be used as a guide for sending for histopathology. In our study we have found that two cases had polyploid mass and one case had thickened wall whereas rest seven $(70 \%)$ of the cases of incidental carcinoma GB had no macroscopic intraoperative findings suggesting the need of routine histopathology of all cholecystectomy sample.

There are few limitations of the study which include the retrospective nature of the study. The shorter follow up period for cases of incidental GB carcinoma and no comparison between laparoscopic and open cholecystectomy while studying the incidence and clinicopathological nature of this disease in this study.

\section{CONCLUSION}

The rate of incidental carcinoma of gall bladder in our setting was found to be $1.28 \%$. Our study strongly recommends routine histopathological examination in all cholecystectomy specimens as they help in detection of majority of cases of occult carcinoma GB. This study also highlights that although primary carcinoma of gall bladder are known for their late presentation and hence poor survival rates; occult carcinoma GB diagnosed incidentally on histopathological examination of post-cholecystectomy specimen are usually detected at earlier stages and thus have better prognosis. 


\section{REFERENCES}

1. Murshid KR. Asymptomatic gallstones: Should we operate? Saudi J Gastroenterol 2007; 13: 57-69.

2. Jemal A, Siegel R, Ward E, Murray T, Smigal C, Thun MJ. Cancer statistics, 2006. CA Cancer J Clin 2006; 56:106-130.

3. Muratore A, Polastri R, Caussotti L. Radical surgery for gallbladder cancer: current options. Eur J Sur Oncol 2000; 5: 438-43.

4. Oddsdottir M, Hunter JG. Gall bladder and the extrahepatic billiary sytem. In: Brunicardi FC, Andersen DK, Billiar TR, Dunn DL, Hunter JG, Pollock RE, editors. Schwartz's principle of surgery (8th ed.). New York: McGraw Hill; 2005.1187-1219.

5. Whang EE, Zinner MJ. Cancer of the Gall bladder and the bile ducts. In: Zinner MJ, Ashley SW, editors. Maingot's abdominal operations (11th ed.). New York: McGraw Hill; 2007. 921-35.

6. Have PC, Simpson KJ, Garden OG. Liver and biliary tract disease. Hasle; C, Chilvers ER, Boon NA, Colldge NR (19th ed.). Churchill Livingstone. 831-88.

7. James MC. Liver and biliary tract. In: Kumar V, Abul KA, Nelson F, editors. Robins and Cotran Pathologic basis of Disease (7th ed.). Philadelphia: Elsevier; 2004. 935.

8. Russel RCG. The gall bladder and bile ducts. In: Russel R.C.G, Williams N.S, Bulstrode C.J.K, editors. Bailey and Love,s short practice of Surgery (24th ed.).London: Hodder Arnold Publication; 2004.1095-1113.

9. Mittal R, Jesudason MR, Nayak S. Selective histopathology in cholecystectomy for gallstone disease. Indian J Gastroenterol 2010; 29: 26-30.

10. Darmas B, Mahmud S, Abbas S, Baker AL. Is there any justification for the routine histological examination of straightforward cholecystectomy specimens? Ann Roy Coll Surg Engl 2007; 89: 238-41.

11. Bazoua G, Hamza N, Lazim T. Do we need histology for a normal-looking gallbladder? Surgeon 2003; 1: 233-5.
12. Eric $\mathrm{CH}$, Lau WY. Gallbladder cancer, a comprehensive review. The Surgeon 2008; 10-19.

13. Misra MC, Guleria S. Management of cancer gallbladder found as a surprise on a resected gallbladder specimen. J Surg Oncol 2006;93:690-8.

14. Contini S, Dalla Valle R, Zinicola R. Unexpected gallbladder cancer after laparoscopic cholecystectomy. Surg Endosc 1999;13:264-7.

15. Amanullah MK, Rizwn AK, Shahid S, Veena M. Occult carcinoma of gallbladder: Incidence and role of simple cholecystectomy. JK- Practitioner 2007; 14: 22-3.

16. Sherestha R, Tiwari M, Ranabhat SK, Aryal G, Rauniyar SK, Shrestha HG. Incidental gallbladder carcinoma: value of routine histological examination of cholecystectomy specimens. Nepal Med Coll J 2010; 12(2): 90-4.

17. Zhang WJ, Xu GF, Zou XP et al. Incidental Gallbladder Carcinoma Diagnosed During or After Laparoscopic Cholecystectomy. World J Surg 2009; 33:2651-6.

18. Naqvi SQH, Mangi IH, Dahri FJ, Khaskheli QA, Akhund AA. Frequency of carcinoma of gall bladder in patients with cholelithiasis. Gomal Journal of Medical Sciences 2005; 3(2): 41-3.

19. Daphna W, Mehrdad H, Noa BJ, Sandbanand AH. Incidental finding of gallbladder carcinoma. Israel Med Assoc J 2002; 4: 334-6.

20. Khoo JJ, Nurul AM. A clinicopathological study of nine cases of gallbladder carcinoma in 1122 cholecystectomies in Johor, Malaysia. Malaysian J Pathol 2008; 30(1):21-6.

21. Royal College of Pathologists. Histopathology and cytopathology of limited or no clinical value. Report of working group of The Royal College of Pathologists, 2nd edition London: Royal College of Pathologists, 2005. 